\title{
BMJ Open Neonatal mortality and leading causes of deaths: a descriptive study in China, 2014-2018
}

Yuxi Liu (D) , ${ }^{1}$ Leni Kang, ${ }^{1}$ Chunhua He, ${ }^{1}$ Lei Miao, ${ }^{1}$ Xiaoqiong Qiu, ${ }^{2}$ Weipeng Xia, ${ }^{3}$ Jun Zhu, ${ }^{1,4}$ Juan Liang, ${ }^{1}$ Qi Li, ${ }^{1}$ Yanping Wang, ${ }^{1}$ Hanmin Liu ${ }^{4,5}$
To cite: Liu Y, Kang L, He C, et al. Neonatal mortality and leading causes of deaths: a descriptive study in China, 2014-2018. BMJ Open 2021;11:e042654. doi:10.1136/ bmjopen-2020-042654

- Prepublication history for this paper is available online. To view these files, please visit the journal online (http://dx.doi. org/10.1136/bmjopen-2020 042654).

YW and $\mathrm{HL}$ contributed equally.

Received 04 August 2020 Revised 19 January 2021 Accepted 19 January 2021
Check for updates

(C) Author(s) (or their employer(s)) 2021. Re-use permitted under CC BY-NC. No commercial re-use. See rights and permissions. Published by BMJ.

For numbered affiliations see end of article.

Correspondence to Professor Yanping Wang; wyxyanping@163.com

\section{ABSTRACT}

Objective The present study estimated the national and urban-rural levels and causes of neonatal deaths in China annually between 2014 and 2018 to provide data support for the further end of preventable neonatal deaths for China and other low-income and middle-income countries. Methods The study was based on data from the National Maternal and Child Health Surveillance System. All neonates of surveillance districts (gestational week: $\geq 28$ weeks) who died after delivery have been involved in the study. The mortality rate and the leading causes of death for neonates were analysed.

Results The neonatal mortality rate (NMR) of China has steadily decreased from 5.9 deaths per 1000 live births in 2014 to 3.9 deaths per 1000 live births in 2018. The NMR in 2018 of urban and rural areas was 2.2 deaths per 1000 live births and 4.7 deaths per 1000 live births, respectively. The leading preventable causes of neonatal deaths are the same in the urban and rural areas were same, which were preterm birth, intrapartum complications and pneumonia. Mortality rates of these three causes fell significantly between 2014 and 2018 but contributed to a higher proportion of deaths in rural areas than urban areas. The proportion of preventable deaths accounted for $74.6 \%$ in 2018.

Conclusions The NMR of China has decreased steadily from 2014 to 2018. However, the inequality between urban and rural areas still exists. The goal of government interventions should be to reduce the health inequality of neonates and further take targeted measures to eliminate preventable neonatal death.

\section{INTRODUCTION}

In 2015, the United Nations summit on sustainable development formally adopted the 2030 agenda for sustainable development. In the Sustainable Development Goals 3 (SDGs3), the goal is to end preventable neonatal and under-five child deaths by $2030,{ }^{1}$ with all countries aiming to reduce neonatal mortality to at least as low as 12 deaths per 1000 live births and under-five mortality to at least as low as 25 deaths per 1000 live births. The importance of newborn health issues has received global attention. The Chinese government has always attached great importance to the

\section{Strengths and limitations of this study}

This is the first study to show the status of neonatal deaths in China from 2014 to 2018.

- The study covers the most geographically extensive newborn population in mainland China.

- The data from the National Maternal and Child Health Surveillance System used in this study have been shown to be representative of mainland China and to be of high quality for the recording of death causes of children under 5 years.

- The system has not covered the prenatal assessment due to design limitations.

survival, protection and development of children, and has made great achievements in reducing child mortality. Professional institutions for maternal and child healthcare began to be established in $1950 .^{2}$ Moreover, the Chinese government has taken the under-five mortality rate (U5MR), the infant mortality rate and other indicators of children's health as assessment targets for provincial governments and has promulgated the National Program of Action for Child Development in China every decade since 1990s. ${ }^{23}$

Globally, there were 5.3 million deaths occurred on children under 5 years in 2018, $47 \%$ of them died during their first month of life. The vast majority of neonatal deaths occur in low-income and middle-income countries. Approximately 73000 neonates died in China in 2018, accounting for about $3.0 \%$ of the total newborn deaths worldwide, ranking sixth in the world. ${ }^{4}$ Moreover, the global decline in neonatal mortality rate (NMR) has been slower than the decline in the U5MR. ${ }^{5}$ Global U5MR declined from 93 per 1000 live births in 1990 to 39 per 1000 live births in 2018, while that of NMR only declined from 37 per 1000 live births to 18 per 1000 live births during the same period. Additionally, a great many studies have shown that neonatal deaths amounting to a large 


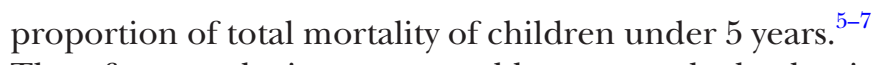
Therefore, reducing preventable neonatal deaths is important to further reduce the U5MR.

China has achieved the Millennium Development Goal 48 years ahead of schedule in $2007,{ }^{8-13}$ and it is also rated by the WHO as a country with 'high performance in maternal and child health'. In 2018, the NMR of China was 3.9 deaths per 1000 live births, which was lower than the target of SDG3. ${ }^{14}$ However, according to the NMR data from World Bank in 2018, the NMR of China is at a low level in developing countries (such as the NMR in Brazil was 8.1 deaths per 1000 live births and Thailand was 5.0 deaths per 1000 live births); it still lags behind that in developed countries (such as the NMR in Australia was 2.3 deaths per 1000 live births and Germany was 2.2 deaths per 1000 live births). ${ }^{15}$ Moreover, since urban areas generally have better economic development than rural areas, resulting in better health service infrastructure and health service infrastructures, ${ }^{16}$ there is an urban-rural inequity in neonatal mortality in China. ${ }^{17}$ To further shorten the gap with developed countries and reduce the difference in neonatal mortality between urban and rural areas, there is still room for improvement in neonatal deaths in China. This study will analyse neonatal mortality trends and its mortality of major causes of death in China from 2014 to 2018 to provide data support for the further elimination of key preventable diseases that can cause neonatal deaths.

\section{MATERIALS AND METHODS \\ Study subjects}

The study covered all the 327 districts of the National Maternal and Child Health Surveillance Districts (with 125 urban districts and 202 rural districts) in 31 provinces, autonomous regions and municipalities of China. Further details about the National Maternal and Child Health Surveillance System have been described elsewhere. ${ }^{18}$

All neonates of surveillance districts (gestational week: $\geq 28$ weeks) who died after delivery and had one of the four vital signs would be involved in surveillance subject, including heartbeat, breath, umbilical cord pulsation and voluntary muscle contraction. The surveillance subjects also includes adoption of children and children of nonlocal household residents whose mothers have been living in the surveillance districts for more than 1 year.

\section{Data collection and quality control}

After each child died in the surveillance districts, the local village doctor (or community doctor) needs to report to the local township health centres (or community health service centres) within 10 days. Local township health centres (or community health service centres) need to be verified within 7 days after reporting and fill the child death report card based on the hospital's death diagnosis. If the child died at home or on the way to the health facilities, infer the cause of death would base on the 2016 WHO Verbal Autopsy Standards ${ }^{19}$ and then fill the child death report card. The classification of diseases is according to the International Classification of Diseases-10.

The children's mortality data were reported level by level, and the data are timely reported through the network direct reporting system. Technical personnel responsible for monitoring work are set up at all levels to complete the collection, review and operation of surveillance data. After that, the child death data would send to the county (or district) level maternal and child health institutions each season. The county (or district) level maternal and child health institutions would report the local child deaths status to prefecture-level and provincelevel maternal and child health institutions each season; the National Office of Maternal and Child Health would summarise and analyse the data finally.

For quality control, we have used the regular level-bylevel on-site quality control system. At the county (district), city and provincial levels, following the requirements of the Chinese Maternal and Child Health Surveillance Work Manual, a multisource data cross-check method is used to complete the on-site quality control work in sampling surveillance districts. The National Office of Maternal and Child Health will select 18 districts in six provinces each year for quality inspection. ${ }^{1718}$

\section{Statistical analysis}

Results were collected in Microsoft Excel and analysed using SPSS V.22.0 (IBM, Armonk, New York, USA). The NMRs of different areas (urban areas and rural areas) and stages (early neonates and late neonates) and the main cause-specific mortality rates were corrected using the average under-reporting rate of the national-level surveillance data quality checks in the past 3 years. The national NMR and the main cause-specific mortality rate were weighted calculated according to the proportion of the urban and rural population in the census. The diagnostic level composition ratio of the neonate is calculated based on the reported child death report card, excluding children who died of accidental injuries. ${ }^{17}$

The Poisson regression model was used to calculate the average annual rate of decline of NMR, cause-of-death mortality and its $95 \% \mathrm{CI}$ in the country, urban and rural areas and its $95 \% \mathrm{CI}$ in early and late neonates, respectively. Linear by linear association in the $\chi^{2}$ test using SPSS software was used to test whether there was a linear downward trend in different regions and causes of death.

\section{Patient and public involvement}

Patients and members of the public were not involved in the design of this study.

\section{RESULT}

\section{The NMR of China from 2014 to 2018}

At the national level, the NMR of China has steadily decreased from 5.9 deaths per 1000 live births in 2014 to 3.9 deaths per 1000 live births in 2018 ( $p<0.001)$; the average annual rate of decline was $10.7 \%$. The NMR of 


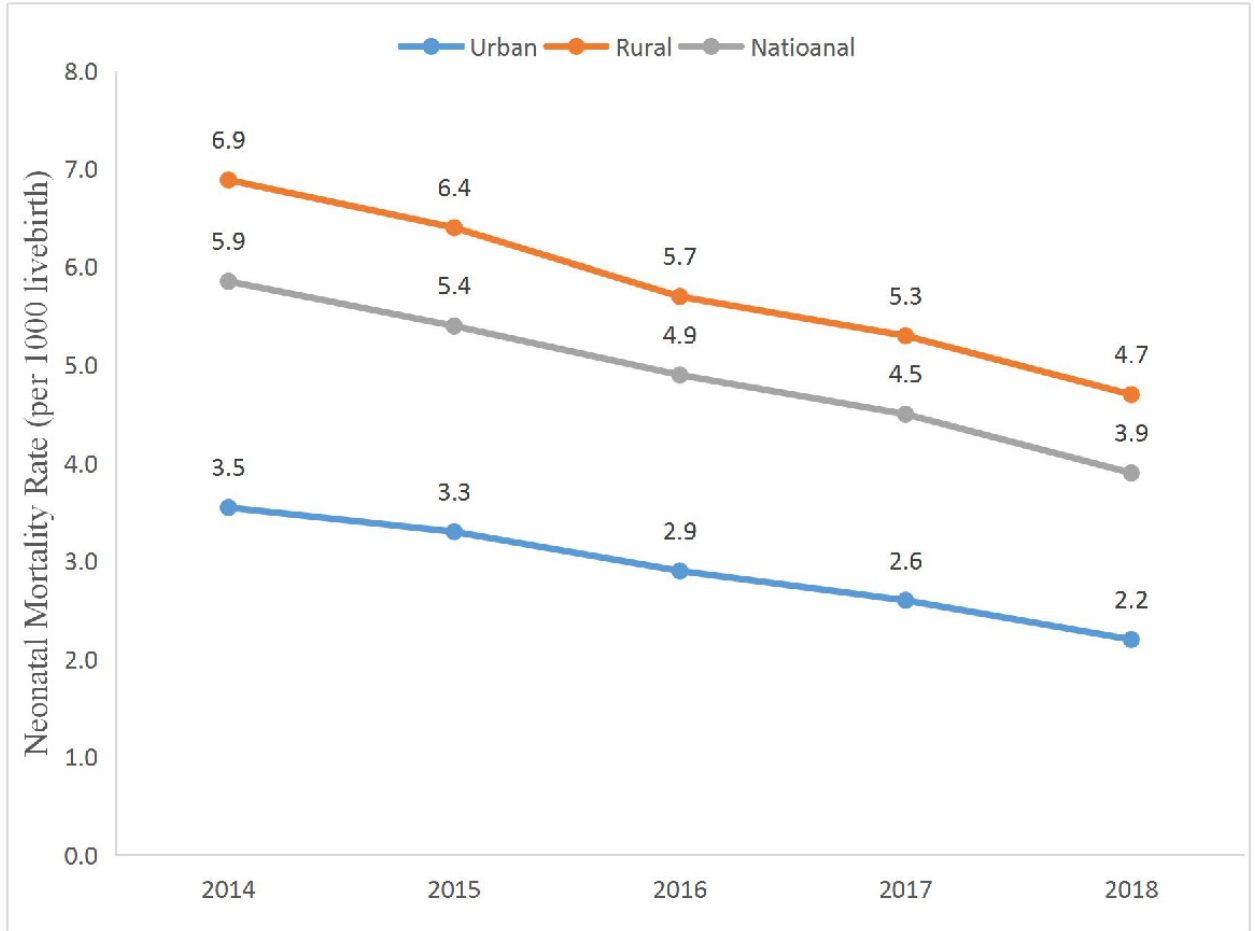

Figure 1 The national and urban-rural neonatal mortality rates (per 1000 live births) in China between 2014 and 2018.

urban and rural areas have both showed a declining trend in the same period $(\mathrm{p}<0.001)$. The mortality rate of urban areas decreased from 3.5 deaths per 1000 live births to 2.2 deaths per 1000 live births, with the average annual rate of decline was $13.0 \%$. In rural areas, the NMR decreased significantly from 2014 to 2018 (6.9 deaths per 1000 live births to 4.7 deaths per 1000 live births, the average annual rate of decline was $10.6 \%, \mathrm{p}<0.001)$. The absolute difference between NMR of urban and rural areas has reduced from 3.4 deaths per 1000 live births to 2.5 deaths per 1000 live births, but the relative difference has increased from 2.0 to 2.2 (see figure 1).

\section{Cause of neonates mortality in China from 2014 to 2018}

Nationwide, compared with 2014, the neonatal deaths caused due to preterm birth, intrapartum complication and pneumonia in 2018 have sharply decreased. Among the particular diseases, the intrapartum complications have the highest average annual decline rate (AADR) from 2014 to 2018 (with 13.5\%, $\mathrm{p}<0.001$ ). The smallest AADR belonged to tetanus (with $0.8 \%, \mathrm{p}<0.05$ ). table 1 All death causes have been divided into preventable diseases and unpreventable diseases to analyse the proportion. In any given year, preterm birth, intrapartum complication and pneumonia were the top three leading causes of preventable neonatal death in China, total accounting for nearly $60 \%$ (see table 1 ). The proportion of preventable diseases reached $73.9 \%$ in 2018. Moreover, the top three diseases at the national level were preterm birth, intrapartum complications and congenital malformations (see figure $2 \mathrm{~A}$ ).

The death cause distribution and AADR were also significantly different among urban-rural areas. In urban areas, preterm birth, intrapartum complication and congenital anomalies also accounting the top three proportion of all deaths cause from 2014 to 2018. Moreover, the AADR of preterm birth, intrapartum complications, pneumonia and congenital malformations in urban areas were all larger than that of the national level. In rural areas, the mortality rate of preterm birth, intrapartum complication and congenital anomalies significantly decreased. Additionally, the NMR of diarrhoea has sharply decreased, with AADR of $25.5 \%(\mathrm{p}<0.001)$ (see table 2).

In contrast, the urban-rural gap still existed. The contribution of tetanus among neonates in urban areas remains 0 during the study period, while the rate in rural areas has been eliminated until 2015. In 2018, the neonatal mortality in rural areas was almost twice as high as in urban areas due to preterm birth, intrapartum complications and congenital malformations. Moreover, during the study period, the largest number of neonatal deaths in the urban and rural areas was pneumonia, which increased from 2.9 times (82.8 per 100000 live births in rural areas vs 28.8 per 100000 live births in urban areas) in 2014 to 3.3 times (44.7 per 100000 live births in rural areas vs 13.5 per 100000 live births in urban areas) in 2018 (see table 2). In the disease proportion aspect, the proportion of intrapartum complications and pneumonia in rural areas significantly higher than that of urban areas (see figure 2B,C). According to the data analysis, causes of neonatal death varied between urban and rural areas $(p<0.05)$, but the correlation between neonatal mortality and whether the newborn lived in urban or rural areas was weak (Cramer's V=0.129). 
Table 1 The proportion of cause-specific neonatal mortality in China from 2014 to 2018

\begin{tabular}{|c|c|c|c|c|c|c|c|c|c|c|c|c|c|c|c|}
\hline \multirow[b]{2}{*}{ Causes of death } & \multicolumn{5}{|c|}{$0-6$ days } & \multicolumn{5}{|c|}{$7-28$ days } & \multicolumn{5}{|c|}{$0-27(<28)$ days } \\
\hline & 2014 & 2015 & 2016 & 2017 & 2018 & 2014 & 2015 & 2016 & 2017 & 2018 & 2014 & 2015 & 2016 & 2017 & 2018 \\
\hline \multicolumn{16}{|l|}{ Nationalwide } \\
\hline Preterm birth & 32.3 & 33.1 & 32.0 & 36.2 & 26.7 & 19.0 & 24.2 & 19.9 & 22.3 & 28.8 & 29.1 & 30.8 & 28.7 & 32.2 & 27.3 \\
\hline Intrapartum complications & 29.0 & 31.9 & 27.0 & 26.4 & 28.5 & 8.4 & 7.1 & 6.0 & 6.2 & 5.6 & 24.2 & 25.5 & 21.4 & 20.6 & 21.7 \\
\hline Pneumonia & 9.5 & 6.9 & 9.0 & 8.0 & 7.9 & 17.3 & 13.5 & 18.0 & 18.2 & 11.5 & 11.3 & 8.6 & 11.4 & 11.0 & 9.0 \\
\hline Diarrhoea & 0.1 & 0.0 & 0.0 & 0.0 & 0.2 & 1.3 & 2.0 & 1.1 & 0.2 & 1.0 & 0.4 & 0.5 & 0.3 & 0.0 & 0.4 \\
\hline Tetanus & 0.0 & 0.0 & 0.0 & 0.0 & 0.0 & 0.6 & 0.0 & 0.0 & 0.0 & 0.0 & 0.1 & 0.0 & 0.0 & 0.0 & 0.0 \\
\hline HIV & 0.0 & 0.0 & 0.0 & 0.0 & 0.0 & 0.0 & 0.0 & 0.0 & 0.0 & 0.0 & 0.0 & 0.0 & 0.0 & 0.0 & 0.0 \\
\hline Neonatal sepsis/meningitis & 1.6 & 2.1 & 2.7 & 2.4 & 3.0 & 5.3 & 4.3 & 7.5 & 5.8 & 9.8 & 2.5 & 2.6 & 4.0 & 3.3 & 5.0 \\
\hline Other infectious diseases & 0.3 & 0.3 & 0.2 & 0.3 & 0.0 & 0.3 & 0.0 & 0.4 & 0.0 & 0.0 & 0.3 & 0.2 & 0.3 & 0.2 & 0.0 \\
\hline Congenital malformations & 15.5 & 12.5 & 16.1 & 16.7 & 19.0 & 23.4 & 22.8 & 26.4 & 22.7 & 22.8 & 17.4 & 15.2 & 18.9 & 18.5 & 20.2 \\
\hline Other diseases & 11.7 & 13.2 & 12.9 & 9.9 & 14.7 & 24.4 & 26.1 & 20.7 & 24.6 & 20.5 & 14.7 & 16.6 & 15.0 & 14.2 & 16.4 \\
\hline \multicolumn{16}{|l|}{ Urban area } \\
\hline Preterm birth & 35.5 & 30.0 & 26.6 & 36.5 & 29.1 & 15.5 & 24.6 & 22.8 & 19.8 & 27.9 & 31.4 & 28.6 & 25.5 & 31.8 & 28.8 \\
\hline Intrapartum complications & 28.0 & 30.0 & 28.2 & 27.8 & 24.3 & 18.1 & 10.4 & 5.5 & 11.2 & 6.4 & 25.9 & 24.6 & 21.8 & 23.2 & 18.7 \\
\hline Pneumonia & 7.3 & 7.9 & 10.7 & 6.4 & 5.3 & 11.3 & 8.2 & 15.1 & 14.5 & 8.1 & 8.1 & 8.0 & 12.0 & 8.6 & 6.1 \\
\hline Diarrhoea & 0.0 & 0.0 & 0.0 & 0.0 & 0.0 & 0.8 & 0.8 & 0.0 & 0.7 & 0.9 & 0.2 & 0.2 & 0.0 & 0.2 & 0.3 \\
\hline Tetanus & 0.0 & 0.0 & 0.0 & 0.0 & 0.0 & 0.0 & 0.0 & 0.0 & 0.0 & 0.0 & 0.0 & 0.0 & 0.0 & 0.0 & 0.0 \\
\hline HIV & 0.0 & 0.0 & 0.0 & 0.0 & 0.0 & 0.0 & 0.0 & 0.0 & 0.0 & 0.0 & 0.0 & 0.0 & 0.0 & 0.0 & 0.0 \\
\hline Neonatal sepsis/meningitis & 2.7 & 2.5 & 4.7 & 4.3 & 8.1 & 3.4 & 7.5 & 8.3 & 12.4 & 12.6 & 2.9 & 3.9 & 5.7 & 6.6 & 9.5 \\
\hline Other infectious diseases & 0.7 & 0.9 & 0.5 & 0.8 & 0.0 & 0.0 & 0.0 & 0.7 & 0.0 & 0.0 & 0.5 & 0.6 & 0.6 & 0.5 & 0.0 \\
\hline Congenital malformations & 17.3 & 16.4 & 17.8 & 16.3 & 15.4 & 32.8 & 28.4 & 24.2 & 20.4 & 26.2 & 20.5 & 19.7 & 19.6 & 17.5 & 18.7 \\
\hline Other diseases & 8.4 & 12.2 & 11.5 & 7.9 & 17.8 & 18.1 & 20.1 & 23.4 & 21.0 & 17.9 & 10.5 & 14.4 & 14.9 & 11.6 & 17.9 \\
\hline \multicolumn{16}{|l|}{ Rural area } \\
\hline Preterm birth & 31.5 & 33.7 & 33.2 & 36.1 & 26.2 & 19.6 & 24.1 & 19.1 & 22.9 & 29.0 & 28.6 & 31.3 & 29.5 & 32.3 & 27.0 \\
\hline Intrapartum complications & 29.2 & 32.3 & 26.8 & 26.1 & 29.3 & 6.4 & 6.2 & 6.1 & 5.2 & 5.4 & 23.8 & 25.7 & 21.3 & 20.1 & 22.3 \\
\hline Pneumonia & 10.0 & 6.7 & 8.7 & 8.4 & 8.4 & 18.6 & 14.8 & 18.7 & 18.9 & 12.4 & 12 & 8.7 & 11.3 & 11.5 & 9.6 \\
\hline Diarrhoea & 0.1 & 0.0 & 0.0 & 0.0 & 0.2 & 1.4 & 2.4 & 1.3 & 0.0 & 1.1 & 0.4 & 0.6 & 0.3 & 0.0 & 0.5 \\
\hline Tetanus & 0.0 & 0.0 & 0.0 & 0.0 & 0.0 & 0.7 & 0.0 & 0.0 & 0.0 & 0.0 & 0.2 & 0.0 & 0.0 & 0.0 & 0.0 \\
\hline HIV & 0.0 & 0.0 & 0.0 & 0.0 & 0.0 & 0.0 & 0.0 & 0.0 & 0.0 & 0.0 & 0.0 & 0.0 & 0.0 & 0.0 & 0.0 \\
\hline Neonatal sepsis/meningitis & 1.3 & 2.0 & 2.2 & 1.9 & 2.0 & 5.7 & 3.5 & 7.4 & 4.3 & 9.1 & 2.4 & 2.4 & 3.6 & 2.6 & 4.1 \\
\hline Other infectious diseases & 0.2 & 0.1 & 0.2 & 0.2 & 0.0 & 0.4 & 0.0 & 0.4 & 0.0 & 0.0 & 0.3 & 0.1 & 0.2 & 0.1 & 0.0 \\
\hline Congenital malformations & 15.1 & 11.7 & 15.7 & 16.8 & 19.8 & 21.4 & 21.4 & 27.0 & 23.3 & 22.0 & 16.6 & 14.1 & 18.7 & 18.7 & 20.4 \\
\hline Other diseases & 12.5 & 13.5 & 13.2 & 10.4 & 14.0 & 25.7 & 27.6 & 20.0 & 25.4 & 21.0 & 15.7 & 17.1 & 15.0 & 14.7 & 16.1 \\
\hline
\end{tabular}

The mortality rates have also shown difference when divided neonates into early neonates (0-6 days) and late neonates (7-27 days). Nationwide, except for neonatal sepsis (or meningitis) and diarrhoea, the mortality rate of other causes of death of early neonates was significantly higher than that of late neonates, with the biggest difference being intrapartum complications, preterm birth and congenital malformations. In 2018, the mortality rate of preterm birth was 73.4 per 100000 live birth in early neonates and 33.2 per 100000 live birth in late neonates. In the same year, the mortality rate of congenital malformations was 52.3 per 100000 live birth in early neonates and 26.2 per 100000 live birth in late neonates. It is worth noting that intrapartum complications were the second leading cause of death among 0-27 days newborns in China from 2014 to 2018, with the mortality rate of 78.2 per 100000 live birth in early neonates and only 6.4 per 100000 live birth in late neonates (see table 2).

Neonate diagnosis facilities level in China between 2014 and 2018

The children's diagnosis facilities level has also be included in surveillance. Nationwide, from 2014 to 
A. Causes of deaths in neonates in China, 2018

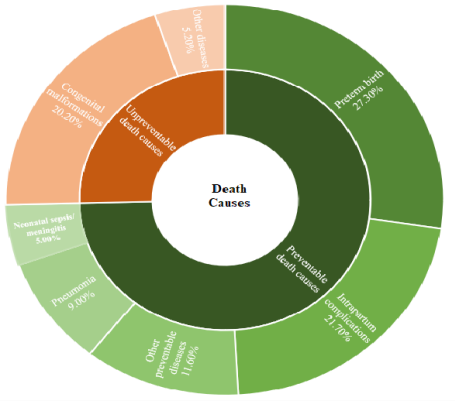

B. Causes of deaths in neonates in urban China, 2018

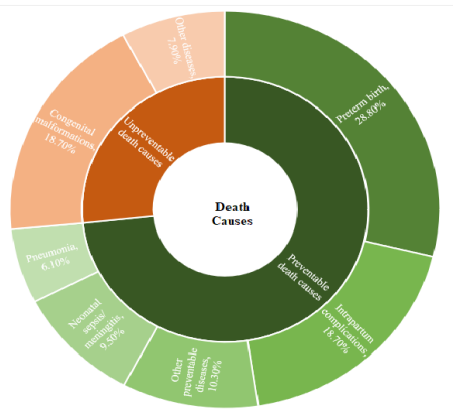

C. Causes of deaths in neonates in rural China, 2018

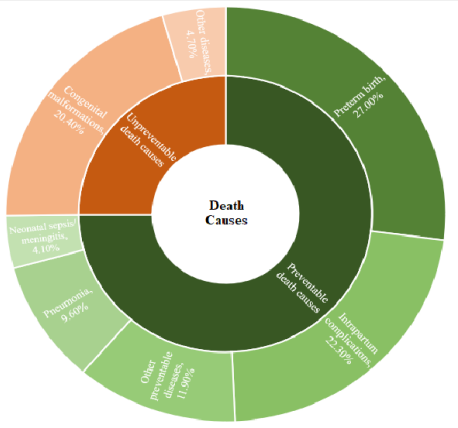

Figure 2 (A) Causes of deaths in neonates in China, 2018. (B) Causes of deaths in neonates in urban China, 2018. (C) Causes of deaths in neonates in rural China, 2018.

2018, the proportion of neonate diagnosis at the provincial (or municipal) level health facilities has significantly increased, and the proportion of the district (or county) level has decreased. Moreover, the proportion of township level and village level have both fluctuating declined during this period. In 2018, the proportion of neonate who has not sought any medical care has minimised, which declined to $3.9 \%$ in 2018 (see figure 3).

In an urban aspect, from 2014 to 2018, the majority of children (accounted for over $80 \%$ ) in urban areas have been diagnosed at provincial (or municipal) level medical facilities. The proportion of the district (or county) level and township level both have a slight rise between 2014 and 2018. As a result, the percentage of children who have not sought medical care has declined, with $1.9 \%$ in 2014 and $1.1 \%$ in 2018 (see figure 3).

On the contrary, the diagnosis contribution figure of rural areas was different. Although the proportion of provincial (or municipal) level has shown a growth trend from 2014 to 2018, the proportion in rural areas have only half of that in urban areas. Moreover, the proportion of street-level diagnoses in the urban area is reduced to $1.4 \%$ in 2018, while this proportion in rural areas fluctuated and remained at $3.7 \%$ in the same year. Another significant contributor is the proportion of children who have not sought medical care. The proportion of neonate who has not sought medical care has decreased, and still, $5.5 \%$ of children have not sought any medical advice (see figure 3 ).

\section{DISCUSSION}

The results of this study show that the NMR in urban and rural areas of China have decreased significantly between 2014 and 2018. In addition, there were significant differences in NMR between urban and rural areas, which were consistent with significant differences in NMR between countries and regions globally. ${ }^{20} 21$

From 2014 to 2018, Chinese NMR continued to decline, and it was dropped quickly. It benefits from the improvement of medical treatment at all levels of health facilities, and all levels of government attached great importance to strengthen the construction of the paediatric institution, raise paediatricians' payment and continue to implement neonatal asphyxia recovery training programme. ${ }^{22}$ As a result, neonatal deaths from pneumonia and infectious diseases, intrapartum complications and premature delivery were significantly reduced.

China has implemented the Safe Maternal Initiative and the National Program to Reduce Maternal Mortality and Eliminate Tetanus; China has officially eliminated neonatal tetanus in $2012,{ }^{23}$ and from 2015 to 2018, the NMR of neonatal tetanus remained 0 . Moreover, through the success of the Prevention of Mother-to-child Transmission of HIV, Syphilis, and Hepatitis B Program, the HIV/AIDS mortality rate has also been 0 from 2014 to 2018. ${ }^{24}$ Although the national neonatal mortality in 2018 was already less than 12 deaths per 1000 live births, the preventable deaths still accounted for $73.9 \%$, mainly were pneumonia, intrapartum complication and premature birth. Among these diseases, the proportion of preterm birth was highest in both nationwide, urban areas and rural areas. In the recent two decades, the prevalence of preterm birth has significantly increased, ${ }^{18}$ especially after the Two-child Policy ${ }^{26}$ was implemented in China. The mortality rate among preterm birth infants was apparently higher than the full-term infant, and the risk of mortality increases proportionally with decreasing gestational age. ${ }^{27}$ Furthermore, with the widespread development of assisted reproductive technique, the incidence of monozygotic twins has increased significantly. ${ }^{28}$ The NMR of twins is several times higher than that of singletons. ${ }^{29-31}$

Addressing the issue of preterm birth may require different priorities in rural and urban areas. Because of the good management of many curable neonatal 


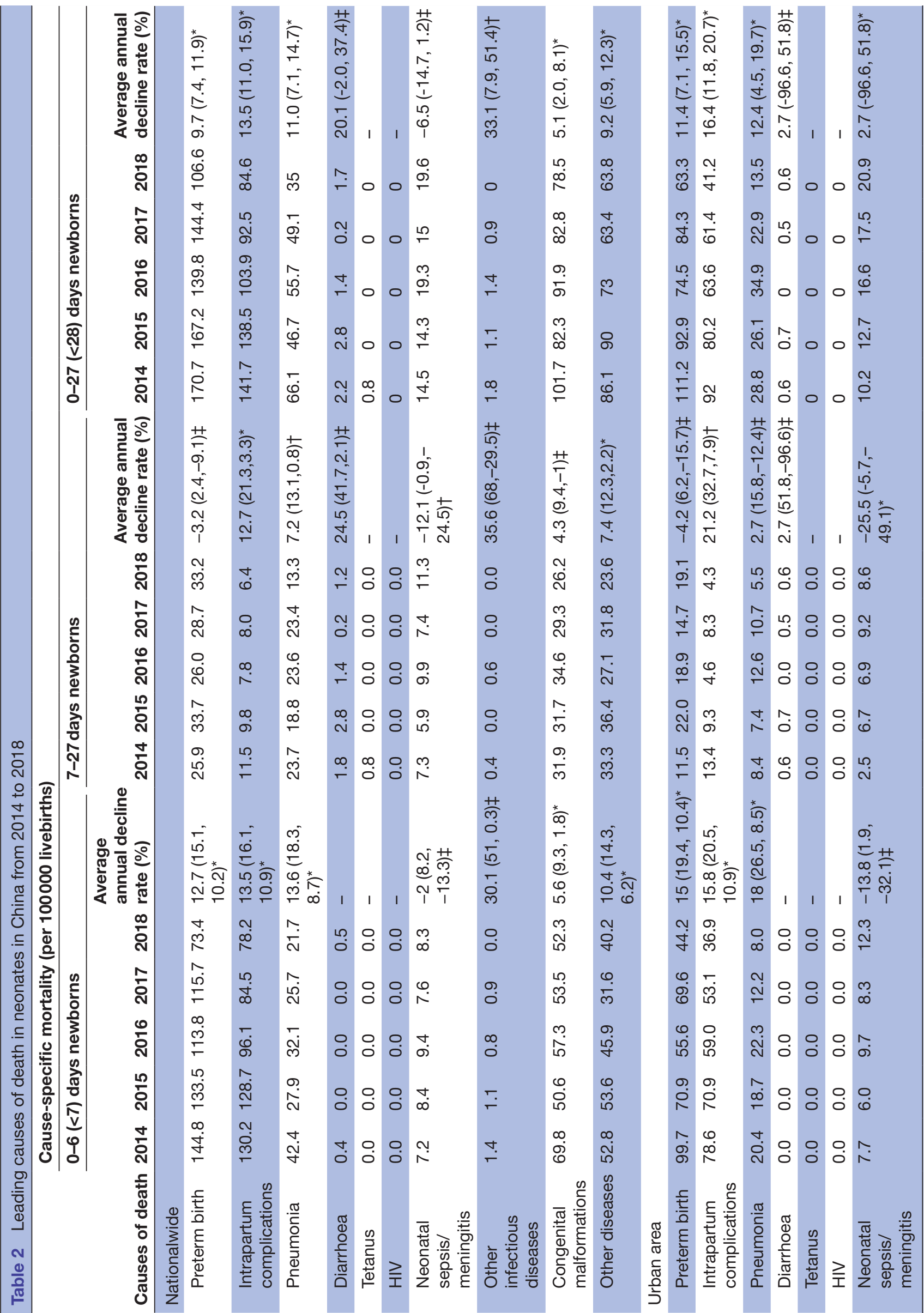




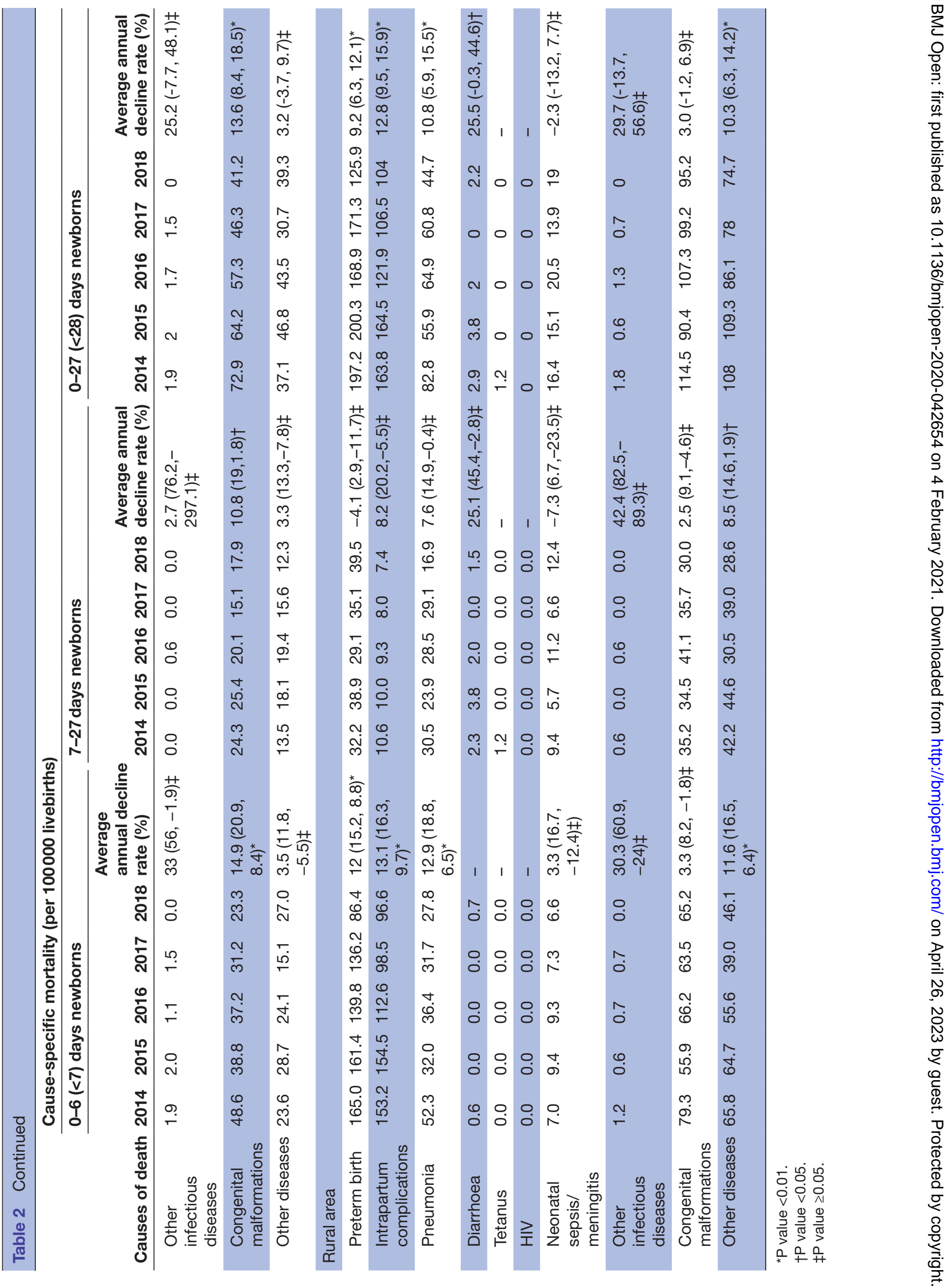




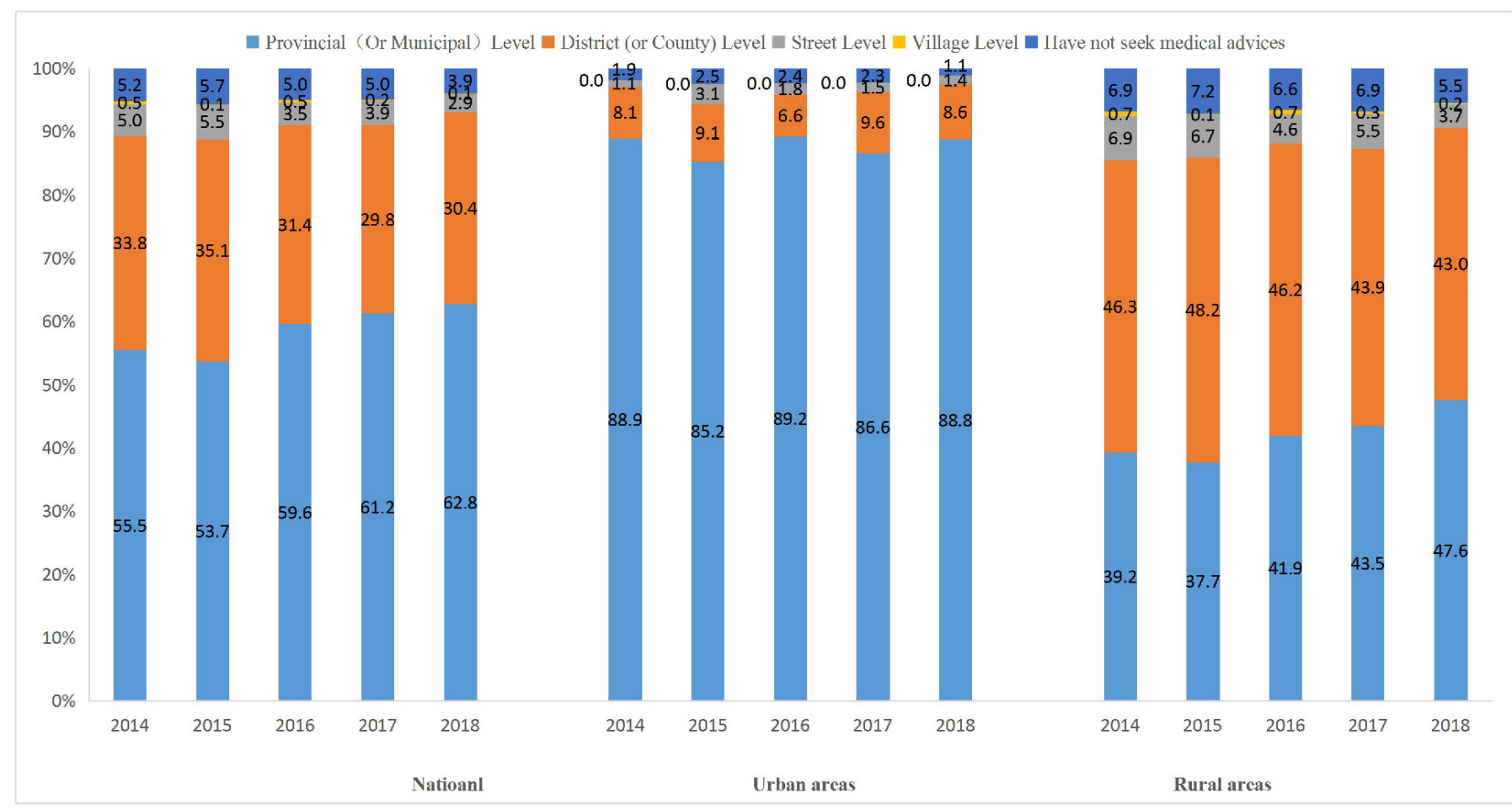

Figure 3 The proportion of neonatal diagnose level in China from 2014 to 2018.

complications (such as pneumonia), the proportion of preterm birth in urban areas is obviously larger than that of rural areas. ${ }^{32}$ Hence, urban areas need to pay more attention to preventing premature deaths less than 32 weeks of gestation. For rural areas, the local government needs to focus on the prevention of premature infants at 32-36 weeks and continue to invest in medical services to improve medical services accessibility for women and children in rural areas.

In addition, from 2014 to 2018, the NMR in rural areas due to preterm birth, intrapartum complications, pneumonia and congenital malformations was decreasing in rural areas but was still significantly higher than in urban areas (see table 2). The higher mortality rate may be linked to the relatively poorer economy, lower quality of healthcare and lack of accessibility to healthcare in rural China. The per capita disposable income was $¥ 39251$ (about US \$6000) in urban China, but $¥ 14617$ (about the US \$2234) in rural China in 2018. ${ }^{33}$ The annual spending on healthcare per capita accounted for $7.8 \%$ in urban China, but $10.2 \%$ in rural China in $2018 .{ }^{34}$ The average healthcare personnel wwere 4.0 per 1000 people in urban China and 1.8 per 1000 people in rural China in 2018. ${ }^{34}$ The number of beds in medical institutions per 1000 people in urban areas was 8.70 , compared with 4.56 in rural areas in 2018. ${ }^{34}$

Not only markedly difference the NMR of urban and rural areas has shown, but also significantly difference in early and late neonates. The results of this study showed that the range of cause-specific mortality of late neonates was significantly less than that of early neonates, both nationwide and urban-rural areas (see table 2).
Therefore, for preventable neonatal diseases, the focus should be on early neonates, especially for early neonates in rural areas.

For neonates, surviving from preterm birth, intrapartum complication and pneumonia are close linking to accessibility to healthcare, local hospitals' obstetrics and neonates departments' treatment level, and rescue skills. ${ }^{35} 36$ Therefore, the issue can be addressed from the following four aspects.

First, the local governments need to strengthen the construction of Regional Neonatal Transport Network, carry out the transport plan according to the Guidelines for the Construction and Management of Critical Neonatal Treatment Center ${ }^{37}$ and ensure the applying of professional medical staff and newborn rescue equipment for neonatal transport. Second, one study in Japan has pointed out that the medical care resources (including neonatal intensive care unit (NICU), midwives, emergency physicians and emergency medical care centres) would impact the NMR decline. ${ }^{38}$ Therefore, the local governments may base on the administration guide (proposal) of the Neonatal Physician Branch of the Chinese Physician Association ${ }^{39}$ to grading neonatal wards and establishing NICU after analysing local medical establishment plan and newborn medical treatment needs. Third, local health departments can regularly organise multilevel, especially provincial, prefecture level and district level newborn health training programmes. In rural areas, with the policies support of the New Rural Construction and the Targeted Poverty Alleviation, ${ }^{40}{ }^{41}$ the improved rural transport and higher incomes have prompted the enhanced accessibility of health services, and the 
proportion of rural children receiving medical treatment in provincial and municipal hospitals has significantly increased. The proportion of rural neonate diagnosis at the provincial (or municipal) level health facilities has significantly increased from $39.2 \%$ to $47.6 \%$ from 2014 to 2018 (see figure 3). Different health facilities can set training objectives for medical staff in each levels and strengthen the newborn treatment technology in each level of health facilities. Especially for the health workers in rural areas, the newborn resuscitation training needs to be specifically strengthened. Fourth, the local communities can strengthen publicity to encourage caregivers to take children to attend the health facilities for treatment. As for poor households, local governments can set up special subsidies for them to reduce the economic cost of medical treatment.

\section{CONCLUSION}

With the joint efforts of the economic development and the governmental policies and strategies, the NMR of China has significantly decreased from 2014 to 2018 . The gap between neonatal mortality and cause-of-death distribution still existed between urban and rural areas. The goal of government interventions should be to narrow the urban-rural gap, reduce the health inequality of neonates and further take targeted measures to eliminate the preventable death of neonates, especially premature births, to achieve the SDGs.

\section{Author affiliations}

${ }^{1}$ National Office of Maternal and Child Health Surveillance of China, West China Second University Hospital, Sichuan University, Chengdu, China

${ }^{2}$ Department of obstetrics and gynecology, Pidu District People's Hospital, Chengdu, China

${ }^{3}$ Department of Pediatrics, Second People's Hospital of Zhaotong, Zhaotong, China

${ }^{4}$ Key Laboratory of Birth Defects and Related Diseases of Women and Children of the Ministry of Education, West China Second University Hospital, Sichuan University, Chengdu, China

${ }^{5}$ Department of Pediatrics, West China Second University Hospital, Sichuan University, Chengdu, China

Acknowledgements We would like to thank the institutions and staff of the National Maternal and Child Health Surveillance System for data collection, data provided and case investigation.

Contributors Data analysis: YL. Methodology: HL, YW and LK. Data curation: JZ, JL, LM, XQ and WX. Software: CH, LK and QL. Writing - original draft: YL. Writing review and editing: $\mathrm{YL}, \mathrm{HL}$ and $\mathrm{YW}$.

Funding This study was supported by the Ministry of Health, China (grants QT2003-009 and 05wsb-02) and UNICEF (grant YH601-11-1141).

Competing interests None declared.

Patient and public involvement Patients and/or the public were not involved in the design, or conduct, or reporting, or dissemination plans of this research.

Patient consent for publication Not required.

Ethics approval This study was approved by the Ethics Committee of West China Second University Hospital, Sichuan University, China.

Provenance and peer review Not commissioned; externally peer reviewed.

Data availability statement Data may be obtained from a third party and are not publicly available. This study used data from the National Maternal and Child Health Surveillance System. This system is coestablished by the National Health and Family Planning Commission of the People Republic of China and Sichuan University and finally owned by the National Health and Family Planning Commission of the People Republic of China. The researchers did not obtain consent to publicly share data. The deidentified data set is available on request to interested researchers. For data requests, please contact the Department of Science and Technology of West China Second University Hospital, Sichuan University, at:fu2yuankjb@163.com.This department is in charge of all the programmes in the hospital, including the data management. One staff from the department monitors this email.

Open access This is an open access article distributed in accordance with the Creative Commons Attribution Non Commercial (CC BY-NC 4.0) license, which permits others to distribute, remix, adapt, build upon this work non-commercially, and license their derivative works on different terms, provided the original work is properly cited, appropriate credit is given, any changes made indicated, and the use is non-commercial. See: http://creativecommons.org/licenses/by-nc/4.0/.

\section{ORCID iD}

Yuxi Liu http://orcid.org/0000-0002-9871-6650

\section{REFERENCES}

1 UN. Sustainable development goals, 2015. Available: https://sustaina bledevelopment.un.org/?menu=1300

2 Department of Maternal and Child Health of China. 2019 report on development of maternal and child health. Beijing, 2019. Available: http://en.nhc.gov.cn/2019-10/11/c 75692.htm [Accessed 12 Mar, 2020].

3 The State Council Information office of the People's Republic of China. The implenmentation of "National Program of Action for Child Development in China in 1990s" and "National Program of Action for Child Development in China (2001-2010)"., 2001. Available: http:// www.china.org.cn/e-news/news01-4-27-1.htm

4 WHO, UNICEF, UN \& World Bank Group. Levels \& trends in child mortality-report 2019; 2019 [Accessed 12th Mar, 2020].

5 WHO. Newborns: reducing mortality, 2019. Available: https://www. who.int/news-room/fact-sheets/detail/newborns-reducing-mortality

$6 \mathrm{CL} \mathrm{Z}$. Analysis of surveillance results of 4074 children under 5 years old. Maternal and Child Health Care of China 2015;30:5095-8.

7 Health Ministry of China. Health statistical Yearbook of China, 1st edn. Beijing, China: Peking Union Medical College Press, 2013: 201.

8 National Working Committee on Children and Women under State Council. National program for women and child development, 2020. Available: http://www.nwccw.gov.cn/node_2427.htm

9 UN. Millennium development goal, 2000. Available: http://www.un. $\mathrm{org} / \mathrm{zh} /$ millenniumgoals/getinvolved.shtml

10 Wang Y, Li X, Zhou M, et al. Under-5 mortality in 2851 Chinese counties, 1996-2012: a subnational assessment of achieving mdg 4 goals in China. Lancet 2016;387:273-83.

11 National Bureau of Statistics of China. China statistical yearbook 2016, 2016. Available: http://www.stats.gov.cn/tjsj/ndsj/2016/ indexch.htm

12 Ministry of Foreign Affairs of China \& UN China. Report on China's implementation of the millennium development goals (2000-2015), 2015. Available: http://cn.chinagate.cn/reports/2015-07/28/content 36164105.htm

13 Kuruvilla S, Schweitzer J, Bishai D, et al. Success factors for reducing maternal and child mortality. Bull World Health Organ 2014;92:533-44.

14 National Bureau of Statistics of China. China public health statistical Yearbook 2018. Beijing, China Peking Union Medical College Publishing House; 2018. http://www.stats.gov.cn/tjsj/ndsj/2018/ indexeh.htm

15 Bank TW. Mortality rate, neonatal (per 1,000 live births), 2019. Available: https://data.worldbank.org/indicator/SH.DYN.NMRT

16 Wang Y, Zhu J, He C, et al. Geographical disparities of infant mortality in rural China. Arch Dis Child Fetal Neonatal Ed 2012;97:F285-90.

$17 \mathrm{He} \mathrm{C}$, Liu L, Chu Y, et al. National and subnational all-cause and cause-specific child mortality in China, 1996-2015: a systematic analysis with implications for the sustainable development goals. Lancet Glob Health 2017;5:e186-97.

18 Lu R, Li X, Guo S, et al. Neonatal mortality in the urban and rural China between 1996 and 2013: a retrospective study. Pediatr Res 2016;79:689-96.

19 Nichols EK, Byass P, Chandramohan D, et al. The who 2016 verbal autopsy instrument: an international standard suitable for automated analysis by InterVA, InSilicoVA, and tariff 2.0. PLoS Med 2018;15:e1002486. 
20 Yaya S, Uthman OA, Okonofua F, et al. Decomposing the rural-urban gap in the factors of under-five mortality in sub-Saharan Africa? Evidence from 35 countries. BMC Public Health 2019;19:616.

21 Saikia N, Singh A, Jasilionis D, et al. Explaining the rural-urban gap in infant mortality in India. Demogr Res;29:473-506.

22 National health commission, National development and reform commission, the Ministry of Education, the Ministry of Finance, the Ministry of human resources and social security \& National Administration of Traditional Chinese Medicine (NATCM). Circular on the issuance of opinions on strengthening the reform and development of children's medical and health services, 2016. Available: http://www.mohrss.gov.cn/SYrlzyhshbzb/shehuibaozhang/ zcwj/yiliao/201606/t20160601_241098.html

23 UNICEF. Maternal and neonatal tetanus eliminated in China, 2012. Available: https://www.unicef.cn/en/press-releases/maternal-andneonatal-tetanus-eliminated-china

24 Wang A-L, Qiao Y-P, Wang L-H, et al. Integrated prevention of mother-to-child transmission for human immunodeficiency virus, syphilis and hepatitis B virus in China. Bull World Health Organ 2015;93:52-6.

25 China CDC. Prevention of mother-to-child transmission of HIV, syphilis and hepatitis B (2011-2013), 2011. Available: http://www. chinacdc.cn/gwswxx/fyzx/201107/t20110704 48397.html

26 Institute of party history and literature of the CPC central committee. Memorabilia of the People's Republic of China (October 1949 September 2019), 2019. Available: http://www.gov.cn/xinwen/201909/27/content_5434223.htm [Accessed 12th Mar, 2020].

27 Boghossian NS, Geraci M, Edwards EM, et al. Morbidity and mortality in small for gestational age infants at 22 to 29 weeks' gestation. Pediatrics 2018;141. doi:10.1542/peds.2017-2533. [Epub ahead of print: 1801 2018]

28 Gee RE, Dickey RP, Xiong X, et al. Impact of monozygotic twinning on multiple births resulting from in vitro fertilization in the United States, 2006-2010. Am J Obstet Gynecol 2014;210:468.e1-468.e6.

29 Imaizumi Y, Hayakawa K. Infant mortality among singletons and twins in Japan during 1999-2008 on the basis of risk factors. Twin Res Hum Genet 2013;16:639-44.

30 Jafarian S, Amiri M, Mobasheri M. The effect of twin birth on neonatal and infant mortality rates: a systematic review. Int J Epidemiol Res 2018;5:113-8.
31 Monden CWS, Smits J. Mortality among twins and singletons in subSaharan Africa between 1995 and 2014: a pooled analysis of data from 90 demographic and health surveys in 30 countries. Lancet Glob Health 2017;5:e673-9.

32 Liang J, Mao M, Dai L, et al. Neonatal mortality due to preterm birth at 28-36 weeks' gestation in China, 2003-2008. Paediatr Perinat Epidemiol 2011;25:593-600.

33 National Bureau of Statistics of China. Personal income and consumer spending in 2018, 2019. Available: http://www.stats.gov. $\mathrm{cn} / \mathrm{tjsj} / \mathrm{zxfb} / 201901 / \mathrm{t} 20190121$ 1645791.html

34 National Bureau of Statistics of China. China health statistics Yearbook 2019. Beijing Peking Union Medical College Publishing House; 2020. http://www.stats.gov.cn/tjsj/ndsj/2019/indexeh.htm

35 World Health Organization, Dept. of reproductive health and research, United nations population fund, UNICEF. Managing newborn problems: a guide for doctors, nurses and midwives; 2003. https://www.who.int/maternal_child_adolescent/documents/ 9241546220/en/ [Accessed 12th Mar,2020].

36 Bryce J, Boschi-Pinto C, Shibuya K, et al. Who estimates of the causes of death in children. Lancet 2005;365:1147-52.

37 The National Health Commission of China. Guidelines for the construction and management of critical neonatal treatment center, 2017. Available: http://www.nhc.gov.cn/fys/s3581/201801/10489489 66a44067974a44187c6a8912.shtml

38 Matsumoto Y, Nakai A, Nishijima Y, et al. Absence of neonatal intensive care units in secondary medical care zones is an independent risk factor of high perinatal mortality in Japan. $J$ Obstet Gynaecol Res 2016;42:1304-9.

39 Neonatal Physician Branch of Chinese Physician Association. Guidelines for graded construction and management of neonatal wards in China (proposal). Chin J App/ Clin Pediatr 2013;3:231-9.

40 Office of the central leading group for financial and economic affairs of China. Five mechanisms of the new socialist countryside, 2006. Available: http://www.gov.cn/test/2006-02/23/content_208488.htm [Accessed 12th Mar, 2020].

41 Zhou Y, Guo Y, Liu Y, et al. Targeted poverty alleviation and land policy innovation: some practice and policy implications from China. Land use policy 2018;74:53-65. 